\title{
Episodic carbonate precipitation in the CM chondrite ALH 84049: An ion microprobe analysis of $\mathrm{O}$ and $\mathrm{C}$ isotopes
}

\author{
Mark Tyra ${ }^{1}$, Adrian Brearley ${ }^{1}$, and Yunbin Guan ${ }^{2},{ }^{1}$ Dept. of Earth and Planetary \\ 5 Sciences, University of New Mexico, Albuquerque, NM 87131, USA (matyra@ unm.edu), \\ ${ }^{2}$ Division of Geological and Planetary Sciences, California Institute of Technology, \\ Pasadena, CA 91125
}

\begin{abstract}
1 Abstract
10 We have determined the $\mathrm{O}$ and $\mathrm{C}$ isotope compositions of dolomite grains and the $\mathrm{C}$ isotope compositions of calcite grains in the highly altered CM1 chondrite, ALH 84049, using Secondary Ion Mass Spectrometry (SIMS). Chemically-zoned dolomite constitutes 0.8 volume percent (vol\%) of the sample and calcite 0.9 vol\%. Thirteen separate dolomite grains have $\delta^{13} \mathrm{C}$ values that range from 37 to $60( \pm 2) \%$, $\delta^{18} \mathrm{O}$ values from 25 to $32( \pm 3)$

$15 \%$, and $\delta^{17} \mathrm{O}$ values from 10 to $16( \pm 3) \%$ (VSMOW). Intragrain $\delta^{13} \mathrm{C}$ values in dolomite vary up to $10 \%$. The $\delta^{13} \mathrm{C}$ values of three calcite grains are distinct from those of dolomite and range from 10 to $13( \pm 2) \%$ (PDB). Calcite and dolomite appear to record different precipitation episodes. Carbon isotope values of both dolomite and calcite in this single sample encompass much of the reported range for CM chondrites; our results

20 imply that bulk carbonate $\mathrm{C}$ and $\mathrm{O}$ isotope analyses may oversimplify the history of carbonate precipitation. Multiple generations of carbonates with variable isotope compositions exist in ALH 84049 and, perhaps, in many CM chondrites. This work shows that one should exercise caution when using a clumped isotope approach to determine the original temperature and the isotopic compositions of water for CM

25 chondrite carbonates. Less altered CM meteorites with more-homogeneous $\mathrm{C}$ isotope compositions, however, may be suitable for bulk-carbonate analyses, but detailed carbonate petrologic and isotopic characterization of individual samples is advised.
\end{abstract}

(C) 2015. This manuscript version is made available under the Elsevier user license

http://www.elsevier.com/open-access/userlicense/1.0/ 


\section{Introduction}

CM chondrites preserve material from the early Solar System and record extensive interaction with water. Although some have been thermally altered (Nakamura, 2005; Schmidt et al., 2005; Nakato et al., 2008), most CM chondrites range from moderately aqueously altered type 2 (CM2) to extensively altered type 1 (CM1) (Zolensky et al., 1997; Rubin et al., 2007; Howard et al., 2009; Alexander et al., 2013; Howard et al.,

35 2015). During aqueous alteration of CM chondrites, water reacted with the fine-grained matrix to form phyllosilicates and reacted with larger chondrule olivine, pyroxene, and other primary anhydrous minerals to varying degrees (Brearley, 2006). Progressive alteration changed the composition of matrix phyllosilicates from Fe-rich to $\mathrm{Mg}$-rich due to elemental redistribution during the alteration process (McSween, 1979; Tomeoka and

40 Buseck, 1985; Browning et al., 1996; Howard et al., 2009; Howard et al., 2015).

CM1 chondrites are highly altered meteorites with essentially $100 \%$ replacement of the primary phases and represent the final stage of progressive aqueous alteration of a CM2-like precursor (Zolensky et al., 1997). The mineralogy and whole-rock O isotope composition of CM1 chondrites indicate slightly higher alteration temperatures and lower

45 water/rock ratios than CM2 chondrites (Zolensky et al., 1997; Rubin et al., 2007). Recent computer modeling of the thermal structure of carbonaceous chondrite parent bodies (Palguta et al., 2010) suggests that temperature can increase with depth or laterally depending upon the proximity to warm upwelling "columns" that develop due to convection. This differs from the simple correlation of increasing temperature with depth

50 that is commonly assumed to have been responsible for the progressive metamorphism of, for example, the ordinary chondrites (Scott and Krot, 2005). CM1 chondrites may, 
therefore, have been altered in warmer, but not necessarily deeper, regions of the $\mathrm{CM}$ parent body.

Carbonates are ubiquitous in CM2 (DuFresne and Anders, 1962; Fuchs et al., 1973;

55 Bunch and Chang, 1980; Johnson and Prinz, 1993; Benedix et al., 2003; Lee et al., 2012) and CM1 chondrites (Riciputi et al., 1994; Zolensky et al., 1997; de Leuw et al., 2010; Lindgren et al., 2012). Calcite is found in most CM2 chondrites, irrespective of their degree of alteration, and is joined by dolomite in highly altered CM2 chondrites like Cold Bokkeveld (Brearley, 2006; Rubin et al., 2007; Lee and Ellen, 2008). Aragonite also is

60 found in CM2 chondrites (Lee and Ellen, 2008). Similarly, CM1 chondrites contain primarily calcite, but also contain dolomite, aragonite, and other carbonates such as breunnerite (Zolensky et al., 1997; Brearley and Hutcheon, 2000; Lee and Ellen, 2008; de Leuw et al., 2010). With each study, the story of aqueous alteration and resultant carbonate precipitation becomes more complex and suggests that carbonates precipitated

65 in multiple stages from a changing fluid(s) (e.g., Brearley, 1998, 2006; de Leuw et al., 2010; Lee et al., 2011; 2012; 2014 ; Tyra et al., 2012).

The bulk $\mathrm{O}$ isotope compositions of $\mathrm{CM} 2$ chondrites have been used to track the isotopic evolution of water from high $\delta^{18} \mathrm{O}, \delta^{17} \mathrm{O}$ and $\Delta^{17} \mathrm{O}$ values as interaction with primary anhydrous silicates progressed (e.g. Clayton and Mayeda, 1984; Clayton and

70 Mayeda, 1999; Young et al., 1999; Young, 2001; Alexander et al., 2015). Carbonate bulk $\mathrm{O}$ isotope analyses have been used in a similar manner to evaluate progressive aqueous alteration in CM chondrites (Clayton and Mayeda, 1988, 1999; Benedix et al., 2003; Tyra et al., 2007). Carbonate bulk $\mathrm{O}$ isotope variability has been reported from one chondrite to another, and also within single meteorites, implying that there is heterogeneity in the 
75 isotopic composition of carbonate grains from one region of the meteorite to another. For instance, Benedix et al. (2003) found that $\delta^{18} \mathrm{O}$ values of different calcite aliquots of Murchison vary by as much as $6 \%$.

Analyses of the stable isotopic compositions of individual carbonate grains using Secondary Ionization Mass Spectrometry (SIMS) have allowed workers to evaluate

80 isotope heterogeneity at a very fine scale. Brearley et al. (1999) and Bonal et al. (2010) used SIMS to analyze calcite in the type $2.5 \mathrm{CM} 2$ chondrite Murchison and found considerable $\mathrm{O}$ isotope heterogeneity between grains. Additionally, Tyra et al. (2012) analyzed individual carbonate grains in a set of Antarctic CM2 chondrites (all type 2.2, paired with EET 96006). They found that $\mathrm{O}$ isotope compositions of Ca-carbonates from

85 one individual meteorite rival the bulk carbonate heterogeneity in $\mathrm{O}$ isotopes reported for all CM2 chondrites. As carbonates with distinct morphological types had correspondingly distinct $\mathrm{O}$ isotope compositions, Tyra et al. (2012) also inferred that at least two precipitation events occurred. These workers, however, did not consider if carbonate compositional variability corresponds to isotope composition. Compositional

90 zoning has been found to be ubiquitous in individual dolomite grains in paired meteorites ALH 84049 and ALH 84051 (Tyra et al., 2010a; Tyra, 2013).

Carbonate bulk-C isotope composition $\left(\delta^{13} \mathrm{C}\right)$ also reflects aqueous alteration, an effect that is postulated to be related to the production of methane during serpentinization (Guo and Eiler, 2007). Guo and Eiler (2007) applied carbonate "clumped isotope

95 thermometry" to CM2 chondrite carbonates and noted a possible link between serpentinization and carbonate $\delta^{13} \mathrm{C}$ composition where: 


$$
\mathrm{ol} / \mathrm{pyx}+\mathrm{H}_{2} \mathrm{O} \rightarrow \mathrm{H}_{2}+\text { serpentine. }
$$

Hydrogen then reduces dissolved bicarbonate to produce methane, which escapes the asteroid:

100

$$
4 \mathrm{H}_{2}+\mathrm{HCO}_{3}^{-} \rightarrow \mathrm{CH}_{4}+\mathrm{OH}^{-}+2 \mathrm{H}_{2} \mathrm{O}
$$

Methane production removes ${ }^{12} \mathrm{C}$ preferentially, which raises the $\delta^{13} \mathrm{C}$ values of the remaining $\mathrm{C}$ in the fluid (Richet et al., 1977; Horita, 2001; Guo and Eiler, 2007). Due to non-equilibrium fractionation, the $\delta^{13} \mathrm{C}$ of methane is hypothesized to be $\sim 90 \%$ lower than that of bicarbonate (Guo and Eiler, 2007). Therefore, as serpentinization progresses,

105 methane production and removal would drive the remaining bicarbonate towards higher $\delta^{13} \mathrm{C}$ values. This change of bicarbonate composition may be reflected in the $\mathrm{C}$ isotope composition of carbonates that precipitate from the fluid (Guo and Eiler, 2007); this effect, however, was not observed in the larger sample set of Alexander et al. (2015).

Here, we present the results of $\mathrm{C}$ and $\mathrm{O}$ isotope analyses of carbonate grains within

110 the CM1 chondrite ALH 84049 whose petrographic context, mineral chemistry, and compositional zoning are well constrained. Oxygen and $\mathrm{C}$ isotope values of these carbonates can provide useful constraints on the conditions and processes of carbonate formation. Carbonate isotope compositions $\left(\delta^{13} \mathrm{C}\right.$ and $\left.\delta^{18} \mathrm{O}\right)$ of $\mathrm{CM} 1$ chondrites have been measured in bulk samples by phosphoric acid dissolution (Grady et al., 1988; Benedix et

115 al., 2003; Alexander et al., 2015), and in-situ in the carbonaceous chondrite fall (2.0 to 2.1) Sutter’s Mill (Jenniskens et al., 2012). This study addresses several questions: 1) Does the composition of dolomite correspond to variations in isotope composition that may reflect evolution of the fluid with time? 2) Do the $\mathrm{C}$ and $\mathrm{O}$ isotope values of 
carbonates co-vary in a way that can be used to constrain processes that affect both the

120 carbonate anions and water? 3) Do C and O isotopic compositions of carbonates record evidence of different populations of carbonates with distinct isotopic compositions? If such populations exist, then the isotopic differences may reflect precipitation at different times during progressive alteration and constrain whether the carbonate phases precipitated from the same fluid. Alternatively, localized variations or differences in

125 isotopic composition may reflect local chemical microenvironments within the meteorite parent body, in which individual carbonates grew from isolated reservoirs of fluid.

\section{Samples and Methods}

\subsection{ALH 84049}

A thin section of ALH 84049 (1" diameter, $30 \mu \mathrm{m}$ thick) was provided by the

130 Antarctic Meteorite Working Group (NASA Johnson Space Center Antarctic Meteorite Collection). Approximately 29.4g of this sample was collected in Antarctica, and it has a weathering grade of Ae with a fracturing grade of B (Score and Lindstrom, 1990). ALH 84049 dolomite was analyzed for its Mn-Cr isotopic systematics in Tyra et al. (2010b) and Tyra (2013): in this study we have determined that ALH 84049 is fully hydrated and

135 should be classified as a CM1 chondrite on the classification scale of 1-3 scale where 1 is hydrated and 3 pristine (e.g., van Schmus and Wood, 1967). Alexander et al. (2013) also notes very high hydration degrees in samples paired with ALH 84049, with all samples paired with ALH 83100 (a set which includes ALH 84049) ranked from 1.1 to 1.2 on their CM and CR chondrite classification scale. Using the phyllosilicate fraction, Howard 140 et al. (2015) also ranked ALH 83100 as almost completely hydrated-1.1. All analyzed 
dolomite grains in ALH 84049 are compositionally zoned in Fe, Mn, Ca, and Mg (Tyra et al., 2010b; Tyra, 2013).

\subsection{Imaging and chemical analyses}

We imaged the entire sample with a digital camera attached to a petrographic

145 microscope. Reflected light, plane-polarized transmitted light, and cross-polarized transmitted light modes were used. The images in each mode were stitched together into one composite image using Hugin [Sourceforge] software, corrected for lens aberrations (e.g., Fig. S2). These maps formed a baseline for locating carbonate grains, to aid navigation on the SIMS, and to document general petrographic textures in the sample.

150 Potential carbonates were verified either optically or by energy dispersive X-ray spectroscopy (EDS) on a scanning electron microscope (SEM, see below).

Following optical microscope characterization, the section of ALH 84049 was imaged with a FEI Quanta 3D Field Emission Gun SEM/Focused Ion Beam (FIB) instrument located in the Department of Earth and Planetary Sciences at the University of

155 New Mexico. Backscattered electron (BSE) images were taken on the SEM using a beam current of $4 \mathrm{nA}$, accelerating voltage of $30 \mathrm{kV}$ at $100 \mathrm{x}$ magnification, and with a $100 \mathrm{~ms}$ dwell time per pixel. The images were combined into a mosaic of the entire thin section using EDAX software. Carbonate grains were verified by EDS using an EDAX Apollo 40 silicon drift detector using EDAX Genesis software.

160 Many carbonate grains were analyzed with wavelength dispersive spectrometry (WDS) X-ray mapping using a JEOL 8200 Superprobe Electron Probe Micro-analyzer (EPMA) at the University of New Mexico. Dolomite grains were mapped at $15 \mathrm{kV}, 20$ 
$\mathrm{nA}$, using a $1 \mu \mathrm{m}$ beam to determine their composition and characterize any chemical zoning. We performed WDS quantitative analyses, calibrated for $\mathrm{Mn}, \mathrm{Mg}, \mathrm{Fe}, \mathrm{Ca}, \mathrm{Sr}$, and

165 Si using spessartine $(\mathrm{Mn})$, dolomite $(\mathrm{Ca}, \mathrm{Mg})$, siderite $(\mathrm{Fe})$, celestite $(\mathrm{Sr})$, and quartz $(\mathrm{Si})$ standards with detection limits of: 0.01 weight percent $(\mathrm{wt} \%)(\mathrm{Ca}), 0.03 \mathrm{wt} \%(\mathrm{Mg}), 0.01$ (Fe), $0.01 \mathrm{wt} \%(\mathrm{Sr}), 0.02 \mathrm{wt} \%(\mathrm{Si})$, and $0.01 \mathrm{wt} \%(\mathrm{Mn})$ after ZAF correction. Silicon was included in the element list to define the edges of the carbonate grains as accurately as possible. Point compositional analyses of carbonates were performed after SIMS analysis

170 to avoid electron beam damage to the minerals that could affect isotope results. Point analyses were performed adjacent (usually within a couple of microns) to the SIMS pits to estimate the chemical composition of the analyzed areas.

\subsection{Ion microprobe work}

For SIMS analysis, we selected dolomite and calcite grains with few or no

175 inclusions, determined either through BSE imaging or X-ray maps, because an inclusion could have a different $\mathrm{O}$ isotope composition or cause variable Instrumental Mass Fractionation (IMF). The selected carbonate grains were analyzed by ion microprobe to determine $\mathrm{C}$ isotope $\left(\delta^{13} \mathrm{C}\right.$ in ten dolomites and three calcium carbonates) and $\mathrm{O}$ isotope $\left(\delta^{17} \mathrm{O}\right.$ and $\delta^{18} \mathrm{O}$ in eight dolomite grains) compositions. Fig.S1, a cross-polarized light

180 mosaic of the entire ALH 84049 thin section used in this study, shows the locations and identification numbers of each analyzed grain within a $7 \mathrm{~mm}^{2}$ region.

The $\mathrm{C}$ and $\mathrm{O}$ isotope composition of carbonates were measured with the Cameca IMS 7f-GEO SIMS at Caltech $\left(\mathrm{Cs}^{+}\right.$primary beam, $10 \mathrm{kV}, \sim 10 \mu \mathrm{m}$ spot size $)$ in different analytical sessions. Secondary ions of $-10 \mathrm{kV}$ were collected under high mass resolution 
185 conditions, with a mass resolving power (MRP) of $~ 5500$ to separate ${ }^{17} \mathrm{O}^{-}$from the ${ }^{16} \mathrm{O}^{1} \mathrm{H}^{-}$interference and a MRP of 3000 to separate ${ }^{13} \mathrm{C}^{-}$from ${ }^{12} \mathrm{CH}^{-}$. The ${ }^{16} \mathrm{O}^{-}$signal was measured with a Faraday cup (FC), and the ${ }^{17} \mathrm{O}^{-}$and ${ }^{18} \mathrm{O}^{-}$signals with an electron multiplier (EM). Both the ${ }^{12} \mathrm{C}^{-}$and ${ }^{13} \mathrm{C}^{-}$signals were measured with the EM. Sample charging was compensated using a negative electron flood gun at $-10 \mathrm{kV}$. Sample data

190 were calibrated for IMF with suitable carbonate standards (calcite, dolomite, magnesite and siderite— see Supplement for details).

After SIMS work was completed, the analyzed grains were re-examined by SEM using BSE imaging (Quanta 3D FEG Dualbeam SEM/FIB at $15 \mathrm{kV}$ and a current of 0.19 nA) (Fig. 1, Fig. S3) to verify that the SIMS analysis spots were located entirely within

195 the target grains and had not sputtered down to any inclusion minerals below the sample surface.

\section{Results}

\subsection{Petrology}

The petrology of the carbonates in ALH 84049 has been discussed in detail in freely-

200 available dissertation by Tyra (2013, http://repository.unm.edu/handle/1928/23161); only a brief description is provided here. Calcite and dolomite are both found in ALH 84049, at near equal proportions ( 0.8 volume percent (vol\%) dolomite, 0.9 vol\% calcite; Tyra, 2013). The grains of both carbonate minerals range from 10 to $50 \mu \mathrm{m}$ in diameter and are randomly distributed. The calcite grains in ALH 84049 are consistent with the "type 1

205 calcite" classification from Tyra et al. (2012); type 1 calcites contain few mineral inclusions, are $10-50 \mu \mathrm{m}$ in diameter, subhedral, and disseminated throughout the matrix. 
In less altered $\mathrm{CM}$ chondrites, some type 1 calcites have tochilinite rims $\left(6 \mathrm{Fe}_{0.9} \mathrm{~S}\right.$. $5(\mathrm{Fe}, \mathrm{Mg})(\mathrm{OH})_{2}$ ), but these are absent in ALH 84049 (and the paired ALH 84051). Unlike in ALH 84051 (Tyra et al., 2009; Tyra et al., 2010b), no vein dolomite or large

210 dolomite aggregates were observed in ALH 84049.

Compositionally, calcite grains are essentially pure $\mathrm{CaCO}_{3}$, with low minor-element concentrations $(<0.5 \mathrm{wt} \%$, Table 1$)$. We do not differentiate calcite from its polymorphs aragonite or vaterite, both of which have also been found as carbonate phases in CM chondrites (Lee and Ellen, 2008; Lee et al., 2012). Rare calcite grains with corroded or

215 embayed margins have been found included within dolomite (Tyra, 2013). Many dolomite grains have variable $\mathrm{MnO}, \mathrm{CaO}, \mathrm{FeO}$ and $\mathrm{MgO}$ compositions (Table 1) that can vary by as much as $4 \mathrm{wt} \%$ within a single grain (Tyra, 2013).

\subsection{Dolomite $\mathrm{O}$ and $\mathrm{C}$ isotope composition}

Table 1 reports the chemical compositions of individual carbonate grains along with 220 their $\mathrm{O}$ and $\mathrm{C}$ isotope compositions ( $\mathrm{O}$ isotope results are reported relative to VSMOW and $\mathrm{C}$ isotope results to $\mathrm{PDB}$ ). The $\delta^{18} \mathrm{O}$ compositions of dolomite grains are variable and range from 25 to $32( \pm 3,2 \sigma) \%$; $\delta^{17} \mathrm{O}$ values vary from 10 to $16( \pm 3,2 \sigma) \%$. Intragrain isotope variability may be significant. For example, we obtained two O isotope SIMS analyses of dolomite a49-5-b8; spot 1 and spot 2 have $\delta^{18} \mathrm{O}$ values of $25 \%$ and $32 \%$,

225 respectively, the lowest and highest values of the entire data set. The two analyses in grain a49-5-b12 also have a significant $\mathrm{O}$ isotope range, but the two analyses in grain a49-5-b13 are identical. 
Dolomite $\mathrm{C}$ isotope compositions in $\mathrm{ALH} 84049$ are heterogeneous; the $\delta^{13} \mathrm{C}$ values range from 37 to $60 \%$ ( $\pm 2 \%, 2 \sigma)$ (Table 1$)$. Three grains were analyzed twice in

230 separate locations on each grain. On one grain, the dolomite a49-6-b3, $\delta^{13} \mathrm{C}$ compositions varied by $\sim 10 \%$ ( $40 \%$ vs. $50 \%$ ) between the two analyses. Calcite $\delta^{13} \mathrm{C}$ values range from 10 to $14 \%$, a much smaller range than dolomite.

\subsection{Isotopic composition vs. carbonate chemistry}

The evidence of compositional zoning in ALH 84049 carbonates suggests that there

235 may have been different periods of carbonate growth (Tyra, 2013). In order to establish if compositionally-distinct growth zones record different $\mathrm{C}$ isotopic compositions, we compared the chemical compositions of areas that are proximal to the SIMS analysis spots. The results are presented with the isotope compositions in Table 1.

Figures $2 \mathrm{a}$ and $2 \mathrm{~b}$ compare compositional data for individual carbonate grains with

240 the measured $\mathrm{O}$ isotope compositions of the grains. The isotope results do not appear to show systematic variations with the $\mathrm{Ca}, \mathrm{Mg}, \mathrm{Fe}$, or $\mathrm{Mn}$ contents of the carbonates. The $\mathrm{C}$ isotope compositions also do not vary with the chemical composition of the dolomite (Figs. 2c and 2d). Furthermore, multiple analyses from the same grain show no correlation between elemental composition and either $\mathrm{O}$ or $\mathrm{C}$ isotopes; pairs of analyses

245 from the same grain are highlighted in Table 1.

\section{Discussion}

Below, we explain that although the $\mathrm{O}$ isotope compositions of dolomite grains fit with expected models of $\mathrm{O}$ isotope compositions during fluid evolution, the differences in $\mathrm{C}$ isotope values between dolomite and calcite are unexpected. Additionally, the variation 
250 in both $\mathrm{O}$ and $\mathrm{C}$ isotope compositions within a sample area that is only $3 \mathrm{~mm}$ wide (Fig. S1) is remarkable, as is the isotopic variation in three out of four dolomite grains with duplicate analyses. We also evaluate if isotope and chemical compositions varied together to examine how the fluid evolved as it precipitated carbonates. Furthermore, we discuss the relationship between the $\mathrm{O}$ isotope compositions of carbonates in the CM1

255 chondrite ALH 84049 with those determined for less altered CM2s. Lastly, we evaluate C isotope evolution and determine mechanisms, including the possibility of methane formation between the precipitation events that formed calcite and dolomite, to explain the difference between calcite and dolomite $\delta^{13} \mathrm{C}$ compositions.

\subsection{O isotopes in carbonates}

260 Although bulk $\mathrm{O}$ isotope values may not always correlate with extent of aqueous alteration in chondrites (Schrader et al., 2011), O isotopes have been used as a marker of aqueous alteration in $\mathrm{CM}$ chondrites because they track the interaction of water with chondrite minerals. In carbonaceous chondrites, $\mathrm{O}$ may have resided in two reservoirs: ${ }^{16} \mathrm{O}$-depleted water created by nebular UV ray self-shielding (Yurimoto and Kuramoto,

265 2004; Lyons and Young, 2005) and ${ }^{16}$ O-rich anhydrous silicates (Clayton et al., 1973; Thiemens and Heidenreich, 1983; Clayton and Mayeda, 1984, 1999; Young et al., 1999; Young, 2001). If we accept a closed-system model for the CM chondrite parent body, water $\mathrm{O}$ isotope composition evolved to lower $\delta^{18} \mathrm{O}, \delta^{17} \mathrm{O}$, and $\Delta^{17} \mathrm{O}$ values with progressive interaction with anhydrous silicates (Clayton and Mayeda, 1999; Benedix et

270 al., 2003). This assumption, however, would not hold true if water - rock interaction occurred in an open system where rock-dominated water flowed from planetesimal interiors outward (Young et al., 1999; Young, 2001). In fact, progressively younger 
carbonates may follow the opposite $\mathrm{O}$ isotope compositional trend as that seen in closed system models. We chose to discuss the data in the context of the closed system model as

275 it seems to describe the data well. However, this is not the only possible perspective, and with a larger data set, other possible models systems should be tested.

Previous SIMS studies have shown that different morphologies of calcite in CM chondrites have different $\mathrm{O}$ isotope compositions (Tyra et al., 2007; Tyra et al., 2012). These morphological groups have the following characteristics. Type 1 calcite grains are 280 smaller $(10-50 \mu \mathrm{m})$ grains interspersed throughout the matrix. Type 2 calcite grains are larger aggregates that range from 50-250 $\mu \mathrm{m}$ in diameter and contain small sulfide or phyllosilicate inclusions. Type 3 calcite grains are veins that may infill cracks. Based on their O isotope compositions, Tyra et al. (2012) showed that type 3 calcites in the CM 2.2 EET 96006 paired set are terrestrial in origin. Subsequent work, however, has discovered 285 calcite veins in CM2 chondrites that are not terrestrial, including bimineralic calcitedolomite veins (Lindgren et al., 2011; Lee et al., 2012). Some of these calcite veins have O isotope compositions similar to type 2 calcite-aggregate grains (Lee et al., 2013).

Type 1 calcite grains have similar O isotope compositions in the CM2 chondrites Murchison and in the EET 96006 pairing group, meteorites with a large range in degree 290 of aqueous alteration (2.5 to 2.2; Rubin et al., 2007; Tyra et al., 2012). Brearley et al. (1999) determined calcite $\delta^{18} \mathrm{O}$ compositions of seven grains in Murchison ranging from 27 to $37 \%$ which reside on the terrestrial fractionation line (TFL). Bonal et al. (2010) analyzed five calcite grains (also in Murchison) and determined calcite $\mathrm{O} \delta^{18} \mathrm{O}$ ranges from, including reported uncertainty, 34 to $37.5 \%$ and $\delta^{17} \mathrm{O}$ from 16.5 to $18.5 \%$; all data 295 plot slightly below the TFL (Fig. 3). The results of both Bonal et al. (2010) and Brearley 
et al (1999) overlap those of one of the two carbonate isotope reservoirs, type 1 calcite, reported in the EET 96006 CM2 chondrite paired set (Tyra et al., 2012). Furthermore, the petrographic descriptions of the analyzed grains in both studies are consistent with their being type 1 grains. Type 2 calcite was not reported by either Bonal et al. (2010) or

300 Brearley et al. (1999), although grains that fit the description of type 2 calcite were documented in Murchison by Benedix et al. (2003). Tyra et al. (2012) argued that the bulk carbonate isotope results of Benedix et al. (2003) imply that both type 1 and type 2 calcites are present in many CM2 chondrites, including Murchison (2.5), Murray (2.4/2.5), Nogoya (2.2), and Cold Bokkeveld (2.2). No calcite grains in ALH 84049 were 305 analyzed for their $\mathrm{O}$ isotope compositions. As discussed below, three major variables (temperature, extent of alteration, and water - rock (W:R) ratio) could have produced the differences in the $\mathrm{O}$ isotope compositions of carbonates between CM1 and CM2 chondrites.

Different temperatures of formation would influence the $\mathrm{O}$ isotope values recorded in

310 carbonate due to differences in carbonate - water isotopic fractionation factors. Both $\delta^{17} \mathrm{O}$ and $\delta^{18} \mathrm{O}$ values of carbonates would lie closer to those of the fluid in CM1 chondrites if temperatures were higher than those experienced by CM2 chondrites (assuming the same source water). Although exact temperatures of CM chondrite alteration are not well constrained, different geothermometers give comparable ranges of 315 temperatures. Clayton and Mayeda (1984) used the O isotopic composition of carbonates and phyllosilicates in CM2 chondrites to calculate their temperatures of formation, assuming that these two phases formed contemporaneously and are in isotopic equilibrium. However, when comparing expected isotope fractionation with measured 
isotope values in phyllosilicates and carbonates, it does not appear that they are in

320 isotopic equilibrium, invalidating the calculated temperatures except for Nogoya (0$25^{\circ} \mathrm{C}$ ) (Benedix et al., 2003). Guo and Eiler (2007) used $\mathrm{C}$ and $\mathrm{O}$ clumped isotopes to determine average temperatures of carbonate precipitation between 20 and $71{ }^{\circ} \mathrm{C}$, although there are some problems with this technique which are discussed further below. Cody et al. (2008) used organothermometry to determine maximum temperatures

325 experienced by the $\mathrm{CM} 2$ chondrites Bells $\left(77 \pm 93^{\circ} \mathrm{C}\right)$ and Murchison $\left(96 \pm 65^{\circ} \mathrm{C}\right)$, but did not examine CM1 chondrites.

Alteration temperatures in CM1 chondrites may have been higher than in CM2 chondrites. Zolensky et al. (1997) noted that, unlike the CM2 chondrites, tochilinite is absent in the CM1s. This lack of tochilinite could be attributed to temperatures of 330 alteration above $120^{\circ} \mathrm{C}$, high $f_{\mathrm{o} 2}$, or low $\int_{\mathrm{s} 2}$ that destabilized tochilinite (Zolensky, 1984; Zolensky et al., 1997). The disappearance of tochilinite may actually occur at even lower temperatures in CM chondrites, based on equilibrium thermodynamic modeling, (Zolensky et al., 1989), although the assumption of equilibrium may not, in fact, be valid for $\mathrm{CM}$ chondrite alteration.

335 In addition to temperature affecting the $\mathrm{O}$ isotope compositions of carbonates, both the $\mathrm{W}: \mathrm{R}$ ratio and degree of aqueous alteration in the chondrites would also change the isotopic composition of water as it interacted with anhydrous minerals. Lower $\mathrm{W}: \mathrm{R}$ ratios result in larger changes in oxygen isotope composition of the water, all other things being equal; increased degree of alteration results in larger changes in oxygen isotope

340 composition for a given water content. The effects of both parameters are similar: water will increasingly take on the isotopic characteristics of the silicates (become more rock 
dominated) and have lower $\delta^{18} \mathrm{O}, \delta^{17} \mathrm{O}$, and $\Delta^{17} \mathrm{O}$ values. Temperature rise, conversely, would simply cause a mass dependent fractionation of the $\delta^{18} \mathrm{O}$ and $\delta^{17} \mathrm{O}$ values of the precipitating carbonates.

345 The $\mathrm{O}$ isotope compositions $\left(\delta^{18} \mathrm{O}, \delta^{17} \mathrm{O}\right)$ of dolomite grains in ALH 84049 overlap or are lower than the $\mathrm{O}$ isotope compositions of type 1 calcites in $\mathrm{CM} 2$ chondrites (Fig. 3). The inset in Figure 3 illustrates the predicted progression of the composition of water with time and alteration. Bulk-carbonate $\mathrm{O}$ isotope data for CM2s suggest that dolomite may have precipitated in a later episode than calcite, or from more evolved water

350 (Benedix et al., 2003). In this study, we did not analyze the $\mathrm{O}$ isotope values of type 1 calcite grains. Therefore, we cannot compare the calcite compositions to those of the dolomite grains to ascertain their place in the $\mathrm{O}$ isotope model described above. However, given the similarity between the fractionation factors of dolomite and calcite $\left[1000 \times \ln \alpha\left(\right.\right.$ at $\left.25^{\circ} \mathrm{C}\right)$ calcite $-\mathrm{H}_{2} \mathrm{O}=28.38 \%$ (O'Neil et al., 1969), $1000 \ln \alpha\left(\right.$ at $\left.25^{\circ} \mathrm{C}\right)$

355 dolomite $-\mathrm{H}_{2} \mathrm{O}=30.97 \%$ (Vasconcelos et al., 2005)], it is unlikely that differences in fractionation at constant temperature are responsible for the observed differences in $\mathrm{O}$ isotope composition.

Even though dolomite grains in ALH 84049 have O isotope compositions that are similar to calcite in other $\mathrm{CM}$ chondrites, dolomite and calcite did not precipitate 360 concurrently. Petrographic evidence presented by Tyra (2013) showed that some calcite grains are included in dolomite and thus precipitated earlier. Furthermore, although more determinations are needed to see how carbonates precipitate under conditions that would be found in $\mathrm{CM}$ chondrite parent bodies (e.g., T, $\mathrm{P}, \mathrm{pH}$, and the activities of $\mathrm{CO}_{3}{ }^{2-}, \mathrm{Mg}$, and $\mathrm{Ca}$ ), calcite precipitation is kinetically faster than dolomite precipitation and 
365 therefore would precipitate first and consume available $\mathrm{CO}_{3}{ }^{2-}$ (Chou et al., 1989;

Arvidson and Mackenzie, 1999, 2000). This argues against cogenetic precipitation from a single fluid, and this may be consistent with observations seen in our studied samples. Other workers have observed, however, far more complex carbonate-mineral precipitation sequences that argue that carbonates in many highly-altered CM chondrites

370 precipitated from different fluids (de Leuw et al., 2010; Lee et al., 2014). Nevertheless, in ALH 84049 the strongest argument against dolomite and calcite co-precipitation is their very different $\mathrm{C}$ isotope compositions as discussed below.

\subsection{Isotopes in carbonates}

To our knowledge, this is the first SIMS study of $\mathrm{C}$ isotope ratios in carbonates in

$375 \mathrm{CM}$ chondrites. Sampling individual grains has allowed us to examine heterogeneities unseen in bulk analyses that may differentiate carbonate types. Figure 4 compares the $\mathrm{C}$ isotope compositions of calcite and dolomite grains in ALH 84049, as well as comparing our data to bulk $\mathrm{C}$ isotope compositions for $\mathrm{CM}, \mathrm{CI}, \mathrm{CV}, \mathrm{CO}$, and $\mathrm{CR}$ carbonaceous chondrite groups (Grady et al., 1988; Guo and Eiler, 2007). Although the $\delta^{13} \mathrm{C}$

380 composition of only three calcite grains were analyzed (and more analyses are needed), these are distinct from the $\delta^{13} \mathrm{C}$ compositions of dolomite (T-test assuming unequal variances, $\mathrm{p}=1.2 \times 10^{-4}$ ).

\subsection{1 $\delta^{13} C$ variations in individual carbonate grains}

ALH 84049 carbonate $\delta{ }^{13} \mathrm{C}$ values cover a range of almost $40 \%$, and variability of 385 up to $10 \%$ was observed within individual grains; this range encompasses much of the data spread seen in all bulk analyses of CM, CR, and CI chondrites (Fig. 4). Even though 
this observed $\mathrm{C}$ isotope heterogeneity would be lost during bulk analyses, there are large $\delta{ }^{13} \mathrm{C}$ heterogeneities amongst bulk CM2 chondrite samples that may arise from varying abundances of the different carbonate populations (Grady et al., 1988; Guo and Eiler, 390 2007; Alexander et al., 2015).

$\mathrm{C}$ isotope heterogeneity could arise because there are many potential $\mathrm{C}$ sources that have variable $\delta^{13} \mathrm{C}$ compositions (Grady et al., 1988; Alexander et al., 1998; Sephton, 2002). For instance, rare $\mathrm{SiC}$ is highly enriched in ${ }^{13} \mathrm{C}\left(\delta^{13} \mathrm{C}\right.$ of up to $1200 \%$ ) and any dissolution, although very unlikely, would raise $\delta^{13} \mathrm{C}$ values of $\mathrm{C}$ in solution (Grady et al.,

395 1988; Brearley, 2006; Davidson et al., 2014). In addition, different species of organic matter have unique $\delta^{13} \mathrm{C}$ compositions; oxidation of these species could have potentially affected the local isotope composition of aqueous carbon (Cody et al., 2005; Le Guillou et al., 2014). Isotopic exchange between carboxyl and dissolved carbonate even may be possible (Herd et al., 2011). Although organic matter $\delta^{13} \mathrm{C}$ has been primarily examined

400 through bulk techniques such as pyrolysis, studies have reported considerable $\delta^{13} \mathrm{C}$ variability in both soluble and insoluble organic matter (Alexander et al., 1998; Sephton et al., 2003; Alexander et al., 2007).

Extant $\mathrm{C}$ isotope heterogeneity requires that the $\mathrm{C}$ did not diffuse completely into its surroundings. There is abundant petrographic evidence that chemical 405 microenvironments existed in CM chondrites during alteration (Brearley, 2006; Palmer and Lauretta, 2011; Tyra, 2013). Because the diffusivities of $\mathrm{CO}_{3}{ }^{2-}$ and cations that define microenvironments, such as $\mathrm{Mn}^{2+}, \mathrm{Fe}^{2+}, \mathrm{Mg}^{2+}$, and $\mathrm{Ca}^{2+}$, are comparable (assuming $25^{\circ} \mathrm{C}$, 
35 ppt salinity, and 1 atm pressure, Boudreau, 1997), it is possible that isotopic microenvironments could exist as well.

\section{$410 \quad 5.2 .2 \quad$ Calcite vs dolomite}

The calcite grains measured here have $\delta^{13} \mathrm{C}$ values from 10 to $13( \pm 2) \%$, much lower than dolomite (37 to $60 \%$ ). At similar temperatures, $\delta^{13} \mathrm{C}$ fractionation factors for calcite are similar to dolomite. For example, calculated equilibrium isotopic fractionation between dolomite and calcite at $100^{\circ} \mathrm{C}$ (assuming 1 atm pressure) is $1.5 \%$ and at $200^{\circ} \mathrm{C}$

415 is $1.0 \%$ (Sheppard and Schwarcz, 1970). The small equilibrium isotopic fractionation between both minerals (and between dissolved carbonate anions and both minerals) is not sufficient to account for the large differences in $\mathrm{C}$ isotope compositions observed here. In ALH 84049, different C sources for the two carbonate populations are necessary.

We consider a probable cause of the differences in $\delta^{13} \mathrm{C}$ compositions is that

420 methane formed between the formation of calcite and dolomite. Methane formation and escape would drive the $\delta^{13} \mathrm{C}$ composition of the remaining $\mathrm{C}$ to higher values (Guo and Eiler, 2007). The difference in $\delta^{13} \mathrm{C}$ values implies that calcite and dolomite could not have precipitated at equilibrium from the same fluid and, therefore, formed at different times. If methane formation and removal in ALH 84049 drove the $\delta^{13} \mathrm{C}$ composition of

425 dissolved carbonate to higher values, then calcite measured here precipitated before dolomite grains. Methane removal would raise the $\mathrm{O}$ fugacity of the remaining aqueous fluid above the stability range of tochilinite (which is not observed). However, magnetite, the expected result of tochilinite breakdown, is not observed either (van de Vusse and Powell, 1983; Browning and Bourcier, 1996). 
If future analyses confirm the small range of $\delta^{13} \mathrm{C}$ compositions reported here for calcite, then minimal C-isotope evolution occurred in the fluid during calcite precipitation. Conversely, the large range of dolomite $\delta^{13} \mathrm{C}$ compositions, along with that reported in bulk analyses may indicate changing $\delta^{13} \mathrm{C}_{\text {fluid }}$ with time. Dolomite may have precipitated from spatially isolated fluids, at different times during continual methane

435 formation, after spatially heterogeneous methane formation created a wide range of $\delta^{13} \mathrm{C}$ in the available carbon, or in discrete episodes such as that postulated by Tyra et al. (2012). Obviously, more data are needed to determine which mechanisms predominated, but it seems that dolomite in ALH 84049 precipitated from the final fraction of a rapidly evolving brine and calcite precipitated earlier when porosity and permeability were 440 higher (Tyra, 2013).

\subsection{Dolomite $\mathrm{O}$ and $\mathrm{C}$ isotope covariance and temperature}

In the six grains analyzed for their $\mathrm{O}$ and $\mathrm{C}$ isotope compositions, we observe no covariance between the isotopes (Fig. 5). If methane production and loss after type 1 calcite formation drove $\delta^{13} \mathrm{C}$ to higher values, as hypothesized above, then this process is

445 not captured in these data; otherwise, a trend of increasing $\delta^{13} \mathrm{C}$ with decreasing $\delta^{18} \mathrm{O}$ and $\delta^{17} \mathrm{O}$ may be expected if methane production coincided with water interaction with anhydrous silicates. Conversely, if local $\mathrm{C}$ sources controlled the $\mathrm{C}$ available for carbonate formation, then we would not expect a consistent relationship between $\mathrm{C}$ and $\mathrm{O}$ isotopes. In Figure 5, our data are compared with the bulk carbonate data for CM 450 chondrites of Guo and Eiler (2007). The two sets of data are similar except that bulk O 
isotope compositions are slightly heavier than in situ analyses of dolomite. This may be a coincidence, as explained below.

Guo and Eiler (2007) used bulk carbonate $\mathrm{O}$ and $\mathrm{C}$ isotopes to determine temperatures of precipitation and proposed that methane formation could explain a

455 relationship between the two isotopes that is independent of their temperature of formation. A difficulty with the application of clumped isotopes to thermometry in CM chondrites, however, is that our work shows that the carbonates present in CM chondrites are isotopically heterogeneous. Furthermore, even at the temperature $\left(25^{\circ} \mathrm{C}\right)$ used in the phosphoric acid extraction by Guo and Eiler (2007), dolomite, if present, can contaminate

460 released $\mathrm{CO}_{2}$ gas by up to $20 \%$ in the nominal 24 hour extraction time (Al-Aasm et al., 1990). The abundance of each carbonate population, therefore, will influence the calculated temperature obtained from this bulk technique. In ALH 84049, we observed 0.9 vol\% calcite and 0.8 vol\% dolomite, very similar proportions. Our work shows that calcite and dolomite are quite different in their $\mathrm{C}$ isotope compositions. Additionally,

465 calcite also may have different $\mathrm{O}$ isotope populations that correlates with their morphologies (Tyra et al., 2012). It is well known that bulk techniques miss local mineralogical heterogeneity; in this case the ramifications are significant. Depending upon the proportions of each generation and type of carbonate in individual samples, the bulk-carbonate isotopic compositions may vary considerably.

\subsection{Dolomite chemical composition and isotopes}

Although the dolomite grains are zoned in their elemental compositions, in ALH84049, within our uncertainties neither $\mathrm{O}$ nor $\mathrm{C}$ isotope compositions change in 
concert with the compositional zoning. One reason for this may be simply that we did not obtain isotope data for the most extreme chemical compositions. Tyra (2013) noted that

475 Mn-rich zones are usually found at grain peripheries, unless they occupy porous interior areas that may be a sign of recrystallization. This study observed up to $\sim 7 \mathrm{~mol} \% \mathrm{MnCO}_{3}$ component in dolomite. For the isotope analyses, most dolomites have 1-3 mol\% $\mathrm{MnCO}_{3}$. SIMS spot placement near a grain edge, where more extreme chemical compositions often occur, risks beam overlap with adjacent grains. We therefore made

480 most isotope analyses near grain centers. Hence, a relationship between chemical composition and isotope composition may not have been observed due to sampling bias.

Although sampling bias is a possibility, a lack of a correlation between the chemical composition and the isotope composition may be due to a reservoir size effect: although $\mathrm{O}$ is a major component of water itself, cations are not. Cation consumption 485 during carbonate precipitation and phyllosilicate formation allowed for a wide range of fluid cation compositions that are preserved in carbonates. Additionally, chemical microenvironments formed through the reaction of water with the heterogeneous mineralogy of CM chondrites (Brearley, 2006). If we were to assume that dolomite precipitated contemporaneously, this could explain the chemical variability of individual

490 dolomite grains, and the large $\mathrm{C}$ isotope variability in dolomites separated by only hundreds of microns (for example, grains 6-b10a and 6-b10b).

\section{Conclusions}


This work has advanced the understanding of aqueous alteration, specifically carbonate precipitation, in the CM parent body. Several new observations that constrain 495 the chemical and isotopic evolution of fluids during carbonate precipitation include:

1. The $\delta^{13} \mathrm{C}$ compositions of dolomite in this one sample span much of the range of bulk analyses of a few different carbonaceous chondrite groups. For the grains that we analyzed, dolomite and calcite $\mathrm{C}$ isotope compositions are distinct, with dolomite $\delta^{13} \mathrm{C}$ values ranging from $\sim 35-60 \%$ and calcite at $\sim 12 \%$. Single dolomite grains can have $\delta^{13} \mathrm{C}$ values that vary by $10 \%$. The analyzed carbonate grains occur within a very spatially restricted area, demonstrating that there were localized variations in the isotopic composition of carbon. It is possible that the $\mathrm{C}$ isotope differences between the two carbonates arose due to bicarbonate reduction to methane that removed ${ }^{12} \mathrm{C}$ preferentially between the times each carbonate precipitated. Conversely, oxidation of isotopically variable C-rich species (e.g., organics) that released $\mathrm{C}$ may account for the $\delta^{13} \mathrm{C}$ heterogeneity of dolomite. More data are needed to assess the heterogeneity of the $\delta^{13} \mathrm{C}$ composition of calcite and its cause.

2. The measured $\mathrm{O}$ isotope compositions of dolomite overlap that of CM2-chondrite type 1 calcite measured in prior studies. Even though dolomite (measured here) and type 1 calcite $\mathrm{O}$ isotope compositions measured in other $\mathrm{CM}$ chondrites are similar, their different $\delta^{13} \mathrm{C}$ compositions make it unlikely that they precipitated together.

3. The six dolomite grains where both $\mathrm{C}$ and $\mathrm{O}$ isotopes were measured in the same grain, have similar values to the bulk CM2 chondrite carbonate measured by Guo 
and Eiler (2007). Because of the very different $\delta^{13} \mathrm{C}$ compositions of calcite and dolomite, and noted differences in $\delta^{18} \mathrm{O}$ in type 1 and type 2 calcite grains throughout CM chondrites, the bulk methodology of Guo and Eiler (2007) may result in inaccurate temperature estimates for carbonate precipitation. To determine temperature accurately, the heterogeneous $\mathrm{O}$ and $\mathrm{C}$ isotope compositions of individual carbonate grains must be accounted for. 


\section{Acknowledgements}

This work was supported by NASA Grant NNG06GG37G and NNX11AK51G to

525 A.J. Brearley (PI), the N.M. Space Grant (M. A. Tyra), and a 2010 Meteoritical Society student travel award (M. A. Tyra). I am grateful for discussions with Scott Jasechko, Maarten de Moor, and Rena Ford. Electron microscopy and electron microprobe analyses were carried out in the Electron Microbeam Analysis Facility, Department of Earth and Planetary Sciences, University of New Mexico, a facility supported by the State of New

530 Mexico. We are particularly grateful to Mike Spilde for his assistance with the SEM and electron microprobe. US Antarctic meteorite samples are recovered by the Antarctic Search for Meteorites (ANSMET) program which has been funded by NSF and NASA, and characterized and curated by the Department of Mineral Sciences of the Smithsonian Institution and Astromaterials Curation Office at NASA Johnson Space Center. Finally,

535 we acknowledge the hard work of Conel Alexander, Monica Grady, Chris Herd (AE) and an anonymous reviewer whose work extensively improved the manuscript.

\section{References}

Al-Aasm Ihsan S., Taylor B. E., and South B. (1990) Stable isotope analysis of multiple carbonate samples using selective acid extraction. Chem. Geol. 80, 119-125.

540 Alexander C. M. O'D., Fogel M., Yabuta H., and Cody G. D. (2007) The origin and evolution of chondrites recorded in the elemental and isotopic compositions of their macromolecular organic matter. Geochim. Cosmochim. Acta 71, 4380-4403.

Alexander C. M. O'D., Howard K. T., Bowden R., and Fogel M. L. (2013) The classification of CM and CR chondrites using bulk $\mathrm{H}, \mathrm{C}$ and $\mathrm{N}$ abundances and isotopic compositions. Geochim. Cosmochim. Acta 123, 244-260.

Alexander C. M. O'D., Bowden R., Fogel M. L., and Howard K. T. (2015) Carbonate abundances and isotopic compositions in chondrites. Meteorit. Planet. Sci. 50, 810-833. 
Alexander C. M. O'D., Russell S. S., Arden J. W., Ash R. D., Grady M. M., and Pillinger C. T. (1998) The origin of chondritic macromolecular organic matter: A carbon and nitrogen isotope study. Meteorit. Planet. Sci. 33, 603-622.

Arvidson R. S. and Mackenzie F. T. (1999) The dolomite problem: Control of precipitation kinetics by temperature and saturation state. Am. J. Sci. 299, 257288.

555 Arvidson R. S. and Mackenzie F. T. (2000) Temperature dependence of mineral precipitation rates along the $\mathrm{CaCO}_{3}-\mathrm{MgCO}_{3}$ join. Aquat. Geochem. 6, 249-256.

Benedix G. K., Leshin L. A., Farquhar J., Jackson T., and Thiemens M. H. (2003) Carbonates in CM2 chondrites: Constraints on alteration conditions from oxygen isotopic compositions and petrographic observations. Geochim. Cosmochim. Acta 67, 1577-1588.

Bonal L., Huss G. R., Krot A. N., and Nagashima K. (2010) Chondritic lithic clasts in the $\mathrm{CB} / \mathrm{CH}$-like meteorite Isheyevo: Fragments of previously unsampled parent bodies. Geochim. Cosmochim. Acta 74, 2500-2522.

Boudreau B. P. (1997) Diagenetic models and their implementation: modelling transport and reactions in aquatic sediments. Springer, New York. pp. 430.

Brearley A. J. (1998) Carbonates in CM carbonaceous chondrites: Complex zoning revealed by high resolution cathodoluminescence studies. Lunar Planet. Sci. XXIX. Lunar Planet. Inst., Houston. \#1246(abstr).

Brearley A. J. (2006) The action of water. In: Lauretta, D. S., Leshin, L. A., and McSween, H. Y. Eds.). Meteorites and the Early Solar System II, University of Arizona Press, Tucson, AZ, 584-624.

Brearley A. J. and Hutcheon I. D. (2000) Carbonates in the CM1 chondrite ALH84034: Mineral chemistry, zoning and Mn-Cr systematics. Lunar Planet. Sci. XXXI. Lunar Planet. Inst., Houston. \#1407(abstr).

575 Brearley A. J., Saxton J. M., Lyon I. C., and Turner G. (1999) Carbonates in the Murchison CM chondrite: CL characteristics and oxygen isotopic compositions. Lunar Planet. Sci. XXX. Lunar Planet. Inst., Houston. \#1301(abstr.).

Browning L. B. and Bourcier W. L. (1996) Tochilinite: A sensitive indication of alteration conditions on the CM asteroidal parent body. Lunar Planet. Sci. XXVII. Lunar Planet. Inst., Houston. 171-172.

Browning L. B., McSween H. Y., and Zolensky M. E. (1996) Correlated alteration effects in CM carbonaceous chondrites. Geochim. Cosmochim. Acta 60, 2621-2633. 
Bunch T. E. and Chang S. (1980) Carbonaceous chondrites .2. Carbonaceous chondrite phyllosilicates and light-element geochemistry as indicators of parent body processes and surface conditions. Geochim. Cosmochim. Acta 44, 1543-1577.

Chou L., Garrels R. M., and Wollast R. (1989) Comparative study of the kinetics and mechanisms of dissolution of carbonate minerals. Chem. Geol. 78, 269-282.

Clayton R. N. and Mayeda T. K. (1984) The oxygen isotope record in Murchison and other carbonaceous chondrites. Earth Planet. Sci. Lett. 67, 151-161.

590 Clayton R. N. and Mayeda T. K. (1988) Isotopic composition of carbonate in EETA79001 and its relation to parent body volatiles. Geochim. Cosmochim. Acta 52, 925-927.

Clayton R. N. and Mayeda T. K. (1999) Oxygen isotope studies of carbonaceous chondrites. Geochim. Cosmochim. Acta 63, 2089-2104.

595 Clayton R. N., Grossman L., and Mayeda T. K. (1973) Component of primitive nuclear composition in carbonaceous meteorites. Science 182, 485-488.

Cody G. D., Alexander C. M. O'D., and Tera F. (2005) NMR studies of chemical structural variation of insoluble organic matter from different carbonaceous chondrite groups. Geochim. Cosmochim. Acta 69, 1085-1097.

600 Cody G. D., Alexander C. M. O'D., Yabuta H., Kilcoyne A. L. D., Araki T., Ade H., Dera P., Fogel M., Militzer B., and Mysen B. O. (2008) Organic thermometry for chondritic parent bodies. Earth Planet. Sci. Lett. 272, 446-455.

Davidson J., Busemann H., Nittler L. R., Alexander C. M. O'D., Orthous-Daunay F. R., Franchi I. A., and Hoppe P. (2014) Abundances of presolar silicon carbide grains in primitive meteorites determined by NanoSIMS. Geochim. Cosmochim. Acta 139, 248-266.

de Leuw S., Rubin A. E., and Wasson J. T. (2010) Carbonates in CM chondrites: Complex formational histories and comparison to carbonates in CI chondrites. Meteorit. Planet. Sci. 45, 513-530.

610 DuFresne E. R. and Anders E. (1962) On the chemical evolution of the carbonaceous chondrites. Geochim. Cosmochim. Acta 26, 1085-1114.

Fuchs L. H., Olsen E., and Jensen J. (1973) Mineralogy, mineral-chemistry, and compositon of the Murchison (C2) meteorite. Smithsonian Contrib. Earth Sci. 10, $1-38$.

615 Grady M. M., Wright I. P., Swart P. K., and Pillinger C. T. (1988) The carbon and oxygen isotopic composition of meteoritic carbonates. Geochim. Cosmochim. Acta 52, 2855-2866. 
Guo W. and Eiler J. M. (2007) Temperatures of aqueous alteration and evidence for methane generation on the parent bodies of the CM chondrites. Geochim. Cosmochim. Acta 71, 5565-5575.

Herd C. D. K., Blinova A., Simkus D. N., Huang Y. S., Tarozo R., Alexander C. M. O'D., Gyngard F., Nittler L. R., Cody G. D., Fogel M. L., Kebukawa Y., Kilcoyne A. L. D., Hilts R. W., Slater G. F., Glavin D. P., Dworkin J. P., Callahan M. P., Elsila J. E., De Gregorio B. T., and Stroud R. M. (2011) Origin and Evolution of Prebiotic Organic Matter As Inferred from the Tagish Lake Meteorite. Science 332, 13041307.

Horita J. (2001) Carbon isotope exchange in the system $\mathrm{CO}_{2}-\mathrm{CH}_{4}$ at elevated temperatures. Geochim. Cosmochim. Acta 65, 1907-1919.

Howard K. T., Benedix G. K., Bland P. A., and Cressey G. (2009) Modal mineralogy of $\mathrm{CM} 2$ chondrites by X-ray diffraction (PSD-XRD). Part 1: Total phyllosilicate abundance and the degree of aqueous alteration. Geochim. Cosmochim. Acta 73, 4576-4589.

Howard K. T., Alexander C. M. O’D, Schrader D. L., and Dyl K. A. (2015) Classification of hydrous meteorites (CR, CM and C2 ungrouped) by phyllosilicate fraction: PSD-XRD modal mineralogy and planetesimal environments. Geochim. Cosmochim. Acta 149, 206-222.

Jenniskens P., Fries M. D., Yin Q. Z., Zolensky M., Krot A. N., Sandford S. A., Sears D., Beauford R., Ebel D. S., Friedrich J. M., Nagashima K., Wimpenny J., Yamakawa A., Nishiizumi K., Hamajima Y., Caffee M. W., Welten K. C., Laubenstein M., Davis A. M., Simon S. B., Heck P. R., Young E. D., Kohl I. E., Thiemens M. H., Nunn M. H., Mikouchi T., Hagiya K., Ohsumi K., Cahill T. A., Lawton J. A., Barnes D., Steele A., Rochette P., Verosub K. L., Gattacceca J., Cooper G., Glavin D. P., Burton A. S., Dworkin J. P., Elsila J. E., Pizzarello S., Ogliore R., Schmitt-Kopplin P., Harir M., Hertkorn N., Verchovsky A., Grady M., Nagao K., 645 Okazaki R., Takechi H., Hiroi T., Smith K., Silber E. A., Brown P. G., Albers J., Klotz D., Hankey M., Matson R., Fries J. A., Walker R. J., Puchtel I., Lee C. T. A., Erdman M. E., Eppich G. R., Roeske S., Gabelica Z., Lerche M., Nuevo M., Girten B., Worden S. P., and Sutter's Mill Meteorite Consortium (2012) Radarenabled recovery of the Sutter's Mill meteorite, a carbonaceous chondrite regolith breccia. Science 338, 1583-1587.

Johnson C. A. and Prinz M. (1993) Carbonate compositions in CM and CI chondrites, and implications for aqueous alteration. Geochim. Cosmochim. Acta 57, 28432852.

Kim S.-T. and O'Neil J. R. (1997) Equilibrium and nonequilibrium oxygen isotope 655 effects in synthetic carbonates. Geochim. Cosmochim. Acta 61, 3461-3475. 
Le Guillou C., Bernard S., Brearley A. J., and Remusat L. (2014) Evolution of organic matter in Orgueil, Murchison and Renazzo during parent body aqueous alteration: In situ investigations. Geochim. Cosmochim. Acta 131, 368-392.

Lee M. R. and Ellen R. (2008) Aragonite in the Murray (CM2) carbonaceous chondrite: Implications for parent body compaction and aqueous alteration. Meteorit. Planet. Sci. 43, 1219-1231.

Lee M. R., Sofe M. R., and Lindgren P. (2011) Evolution of carbonate mineralization in the CM2 carbonaceous chondrites. Lunar Planet. Sci. XLII. Lunar Planet. Inst., Houston. \#1710(abstr).

665 Lee M. R., Lindgren P., and Sofe M. R. (2014) Aragonite, breunnerite, calcite and dolomite in the CM carbonaceous chondrites: High fidelity recorders of progressive parent body aqueous alteration. Geochim. Cosmochim. Acta 144, 126156.

Lee M. R., Lindgren P., Sofe M. R., Alexander C. M. O'D., and Wang J. (2012) Extended chronologies of aqueous alteration in the CM2 carbonaceous chondrites: Evidence from carbonates in Queen Alexandra Range 93005. Geochim. Cosmochim. Acta 92, 148-169.

Lee M. R., Sofe M. R., Lindgren P., Starkey N. A., and Franchi I. A. (2013) The oxygen isotope evolution of parent body aqueous solutions as recorded by multiple carbonate generations in the Lonewolf Nunataks 94101 CM2 carbonaceous chondrite. Geochim. Cosmochim. Acta 121, 452-466.

Lindgren P., Lee M. R., and Sofe M. (2012) Evidence for multiple fluid pulses in the CM1 carbonaceous chondrite parent body. Lunar Planet. Sci. 43. Lunar Planet. Inst., Houston. \# 1949(abstr).

680 Lindgren P., Lee M. R., Sofe M., and Burchell M. J. (2011) Microstructure of calcite in the CM2 carbonaceous chondrite LON 94101: Implications for deformation history during and/or after aqueous alteration. Earth Planet. Sci. Lett. 306, 289298.

Lyons J. R. and Young E. D. (2005) CO self-shielding as the origin of oxygen isotope 685 anomalies in the early solar nebula. Nature 435, 317-320.

McSween H. Y. (1979) Alteration in CM carbonaceous chondrites inferred from modal and chemical variations in matrix. Geochim. Cosmochim. Acta 43, 1761-1770.

Nakamura T. (2005) Post-hydration thermal metamorphism of carbonaceous chondrites. J. Mineral. Petrol. Sci. 100, 260-272.

690 Nakato A., Nakamura T., Kitajima F., and Noguchi T. (2008) Evaluation of dehydration mechanism during heating of hydrous asteroids based on mineralogical and 
chemical analysis of naturally and experimentally heated CM chondrites. Earth Planets and Space 60, 855-864.

O'Neil J. R., Clayton R. N., and Mayeda T. K. (1969) Oxygen isotope fractionation in divalent metal carbonates. J. Chem. Phys. 51, 5547-5558.

Palguta J., Schubert G., and Travis B. J. (2010) Fluid flow and chemical alteration in carbonaceous chondrite parent bodies. Earth Planet. Sci. Lett. 296, 235-243.

Palmer E. E. and Lauretta D. S. (2011) Aqueous alteration of kamacite in CM chondrites. Meteorit. Planet. Sci. 46, 1587-1607.

700 Richet P., Bottinga Y., and Javoy M. (1977) Review of hydrogen, carbon, nitrogen, oxygen, sulfur, and chlorine stable isotope fractionation among gaseous molecules. Annu. Rev. Earth Planet. Sci. 5, 65-110.

Riciputi L. R., McSween H. Y., Johnson C. A., and Prinz M. (1994) Minor and traceelement concentrations in carbonates of carbonaceous chondrites, and implications for the compositions of co-existing fluids. Geochim. Cosmochim. Acta 58, 1343-1351.

Rubin A. E., Trigo-Rodriguez J. M., Huber H., and Wasson J. T. (2007) Progressive aqueous alteration of CM carbonaceous chondrites. Geochim. Cosmochim. Acta 71, 2361-2382.

710 Schmidt M., Xeflide S., Botz R., and Mann S. (2005) Oxygen isotope fractionation during synthesis of $\mathrm{CaMg}$-carbonate and implications for sedimentary dolomite formation. Geochim. Cosmochim. Acta 69, 4665-4674.

Schrader D. L., Franchi I. A., Connolly H. C., Greenwood R. C., Lauretta D. S., and Gibson J. M. (2011) The formation and alteration of the Renazzo-like 715 carbonaceous chondrites I: Implications of bulk-oxygen isotopic composition. Geochim. Cosmochim. Acta 75, 308-325.

Score R. and Lindstrom M. M. (1990) Guide to the U.S. collection of Antarctic meteorites 1976-1988. Antarctic Meteorite Newsletter 13, 40,41,88.

Scott E. R. D. and Krot A. N. (2005) Chondritic meteorites and the high-temperature nebular origins of their components. In: Krot, A. N., Scott, E. R. D., and Reipurth, B. Eds.). Chondrites and the Protoplanetary disk, ASP Conference Series, 15-53.

Sephton M. A. (2002) Organic compounds in carbonaceous meteorites. Nat. Prod. Rep. 19, 292-311.

Sephton M. A., Verchovsky A. B., Bland P. A., Gilmour I., Grady M. M., and Wright I. P. (2003) Investigating the variations in carbon and nitrogen isotopes in carbonaceous chondrites. Geochim. Cosmochim. Acta 67, 2093-2108. 
Sheppard S. M. F. and Schwarcz H. P. (1970) Fractionation of carbon and oxygen isotopes and magnesium between coexisting metamorphic calcite and dolomite. Contrib. Mineral. Petrol. 26, 161-198.

730 Thiemens M. H. and Heidenreich J. E. (1983) The Mass-Independent Fractionation of Oxygen: A Novel Isotope Effect and Its Possible Cosmochemical Implications. Science 219, 1073-1075.

Tomeoka K. and Buseck P.R. (1985) Indicators of aqueous alteration in CM carbonaceous chondrites: Microtextures of a layered mineral containing Fe, S, O, and Ni. Geochim. Cosmochim. Acta 49, 2149-2163.

Tyra M. A. (2013) Using oxygen and carbon stable isotopes, ${ }^{53} \mathrm{Mn}-{ }^{53} \mathrm{Cr}$ isotope systematics, and petrology to constrain the history of carbonates and water in the $\mathrm{CR}$ and $\mathrm{CM}$ chondrite parent bodies. Ph.D. Thesis, University of New Mexico.

Tyra M. A., Brearley A. J., and Guan Y. (2010a) SIMS in-situ carbon and oxygen isotopic composition of dolomite and calcite in CM1/2 ALH 84049. Meteorit. Planet. Sci. 45, A204.

Tyra M. A., Matzel J., Brearley A. J., and Hutcheon I. D. (2010b) Variability in carbonate petrography and NanoSIMS ${ }^{53} \mathrm{Mn} /{ }^{53} \mathrm{Cr}$ systematics in paired CM1 chondrites ALH 84051, ALH 84049, and ALH 84034. Lunar Planet. Sci. XLI. Lunar Planet. Inst., Houston. \#2687(abstr).

Tyra M. A., Farquhar J., Guan Y., and Leshin L. A. (2012) An oxygen isotope dichotomy in CM2 chondritic carbonates-A SIMS approach. Geochim. Cosmochim. Acta 77, 383-395.

Tyra M. A., Brearley A. J., Hutcheon I. D., Ramon E., Matzel J., and Weber P. (2009) Carbonate formation timescales vary between CM1 chondrites ALH84051 and ALH84034. Lunar Planet. Sci. XL. Lunar Planet. Inst., Houston. \#2474(abstr).

Tyra M. A., Farquhar J., Wing B. A., Benedix G. K., Jull A. J. T., Jackson T., and Thiemens M. H. (2007) Terrestrial alteration of carbonate in a suite of Antarctic CM chondrites: Evidence from oxygen and carbon isotopes. Geochim. Cosmochim. Acta 71, 782-795.

van de Vusse R. and Powell R. (1983) The interpretation of pyrrhotite-pentlanditetochilinite-magnetite-magnesite textures in serpentines from Mount Keith, Western Australia. Mineral. Mag. 47, 501-505.

van Schmus R. and Wood J. A. (1967) A chemical-petrologic classification for chondritic meteorites. Geochim. Cosmochim. Acta 31, 747-765.

Vasconcelos C., McKenzie J. A., Warthmann R., and Bernasconi S. M. (2005) Calibration of the delta O-18 paleothermometer for dolomite precipitated in microbial cultures and natural environments. Geology 33, 317-320. 
Young E. D. (2001) The hydrology of carbonaceous chondrite parent bodies and the evolution of planet progenitors. Phil. Trans. R. Soc. Lond. A. 359, 2095-2110.

Young E. D., Ash R. D., England P., and Rumble D. (1999) Fluid flow in chondritic parent bodies: Deciphering the compositions of planetesimals. Science 286, 13311335 .

Yurimoto H. and Kuramoto K. (2004) Molecular cloud origin for the oxygen isotope heterogeneity in the solar system. Science 305, 1763-1766.

Zolensky M. E. (1984) Hydrothermal alteration of CM carbonaceous chondrites Implications of the identification of tochilinite as one type of meteoritic PCP. Meteoritics 19, 346-347.

Zolensky M. E., Bourcier W. L., and Gooding J. L. (1989) Aqueous alteration on the hydrous asteroids - Results of EQ3/6 computer-simulations. Icarus 78, 411-425.

Zolensky M. E., Mittlefehldt D. W., Lipschutz M. E., Wang M.S., Clayton R. N., Mayeda T. K., Grady M. M., Pillinger C. T., and Barber D. (1997) CM chondrites exhibit the complete petrologic range from type 2 to 1 . Geochim. Cosmochim. Acta 61 , 5099-5115. 
Table 1. Isotopic and chemical composition of carbonate grains

\begin{tabular}{|c|c|c|c|c|c|c|c|c|c|c|c|c|}
\hline grain & $\delta^{18} 0(\%)$ & $1 \sigma(\%)$ & $\delta^{17} 0(\% \circ)$ & $1 \sigma(\%)$ & $\Delta^{17} \mathrm{O}(\%$ ) & $1 \sigma(\%)$ & $\delta^{13} \mathrm{C}(\% \circ)$ & $1 \sigma(\%)$ & $\mathrm{CaCO}_{3} *$ & $\mathrm{MgCO}_{3} *$ & $\mathrm{FeCO}_{3} *$ & $\mathrm{MnCO}_{3}{ }^{*}$ \\
\hline \multicolumn{13}{|l|}{ dolomite } \\
\hline a49-5_b5_1 & 27.9 & 1.8 & 14.1 & 1.5 & -0.4 & 1.6 & -- & -- & 49.45 & 44.86 & 3.13 & 2.56 \\
\hline a49-5_b55_1 & 28.8 & 1.7 & 15.9 & 1.6 & 0.9 & 1.6 & -- & -- & 51.09 & 42.48 & 4.54 & 1.88 \\
\hline a49-5_b6_1 & 29.4 & 1.7 & 14.5 & 1.5 & -0.8 & 1.6 & -- & -- & 51.48 & 42.69 & 3.78 & 2.04 \\
\hline a49-5_b8_1 & 25.4 & 1.7 & 11.8 & 1.4 & -1.4 & 1.5 & 43.1 & 3.2 & 51.00 & 43.42 & 3.21 & 2.37 \\
\hline a49-5_b8_2 & 32.3 & 1.8 & 15.3 & 1.5 & -1.5 & 1.6 & 46.7 & 1.4 & 48.86 & 43.75 & 5.31 & 2.08 \\
\hline a49-5_b88_1 & 29.4 & 1.7 & 13.2 & 1.6 & -2.1 & 1.7 & -- & -- & 51.09 & 41.72 & 5.41 & 1.78 \\
\hline a49-5_b9_1 & 26.4 & 1.7 & 10.6 & 1.3 & -3.1 & 1.4 & 37.4 & 0.8 & 52.54 & 39.56 & 5.83 & 2.06 \\
\hline a49-5_b12_1 & 25.9 & 1.6 & 10.3 & 1.5 & -3.1 & 1.5 & 59.8 & 1.1 & 50.70 & 42.99 & 4.29 & 2.02 \\
\hline a49-5_b12_2 & 30.4 & 1.6 & 15.0 & 1.4 & -0.8 & 1.4 & 54.5 & 1.1 & 47.19 & 39.71 & 8.18 & 4.91 \\
\hline a49-5_b13_1 & 28.9 & 1.6 & 13.3 & 1.4 & -1.7 & 1.5 & 56.5 & 1.1 & 49.49 & 42.12 & 5.74 & 2.64 \\
\hline a49-5_b13_2 & 29.6 & 1.7 & 15.9 & 1.6 & 0.4 & 1.6 & -- & -- & 48.66 & 42.00 & 7.39 & 1.94 \\
\hline a49_6_b3_1 & -- & -- & -- & -- & -- & -- & 40.2 & 0.8 & 50.93 & 43.19 & 3.83 & 2.06 \\
\hline a49_6_b3_2 & -- & -- & -- & -- & -- & -- & 50.5 & 1.0 & 50.93 & 43.19 & 3.83 & 2.06 \\
\hline a49_6_b4_1 & -- & -- & -- & -- & -- & -- & 45.9 & 0.8 & 44.41 & 40.22 & 8.46 & 6.91 \\
\hline a49_6_b6_1 & -- & -- & -- & -- & -- & -- & 49.5 & 1.0 & 49.15 & 43.60 & 3.14 & 4.12 \\
\hline a49-6-b9_1 & -- & -- & -- & -- & -- & -- & 37.0 & 1.3 & 50.62 & 41.48 & 4.72 & 3.17 \\
\hline a49-6-b10a_1 & -- & -- & -- & -- & -- & -- & 52.7 & 1.2 & 49.16 & 44.64 & 4.02 & 2.19 \\
\hline a49-6-b10b_2 & -- & -- & -- & -- & -- & -- & 39.3 & 1.0 & 48.91 & 44.26 & 4.71 & 2.12 \\
\hline calcite & -- & -- & -- & -- & -- & -- & & & & & & \\
\hline a49_2_b7cal & -- & -- & -- & -- & -- & -- & 13.7 & 0.8 & 98.06 & 0.49 & 1.32 & 0.13 \\
\hline a49_5b2a_1 & -- & -- & -- & -- & -- & -- & 11.9 & 0.7 & 98.82 & 0.24 & 0.88 & 0.06 \\
\hline a49_6_b5_2 & -- & -- & -- & -- & -- & -- & 9.7 & 1.2 & 98.46 & 0.21 & 0.92 & 0.42 \\
\hline
\end{tabular}

Shaded areas denote multiple analyses of one grain. Compositions are adjacent to SIMS spots but not exactly coincident. ${ }^{*} \mathrm{~mol} \%$.

$\Delta^{17} \mathrm{O}=10^{3} *\left[\left(1=\delta^{17} \mathrm{O} / 1000\right)-\left(1+\delta^{18} \mathrm{O} / 1000\right)^{0.5247}\right] \approx \delta^{17} \mathrm{O}-0.52 * \delta^{18} \mathrm{O}$ 


\section{Figures}

Figure 1. BSE images of selected carbonates analyzed by SIMS. Green ellipses denote 785 areas analyzed for $\delta^{13} \mathrm{C}$ and orange ellipses were analyzed for oxygen isotope composition. Unlike many CM2 chondrite calcite grains, none of the grains are rimmed by tochilinite; "dol" is dolomite and "cal" is calcite.
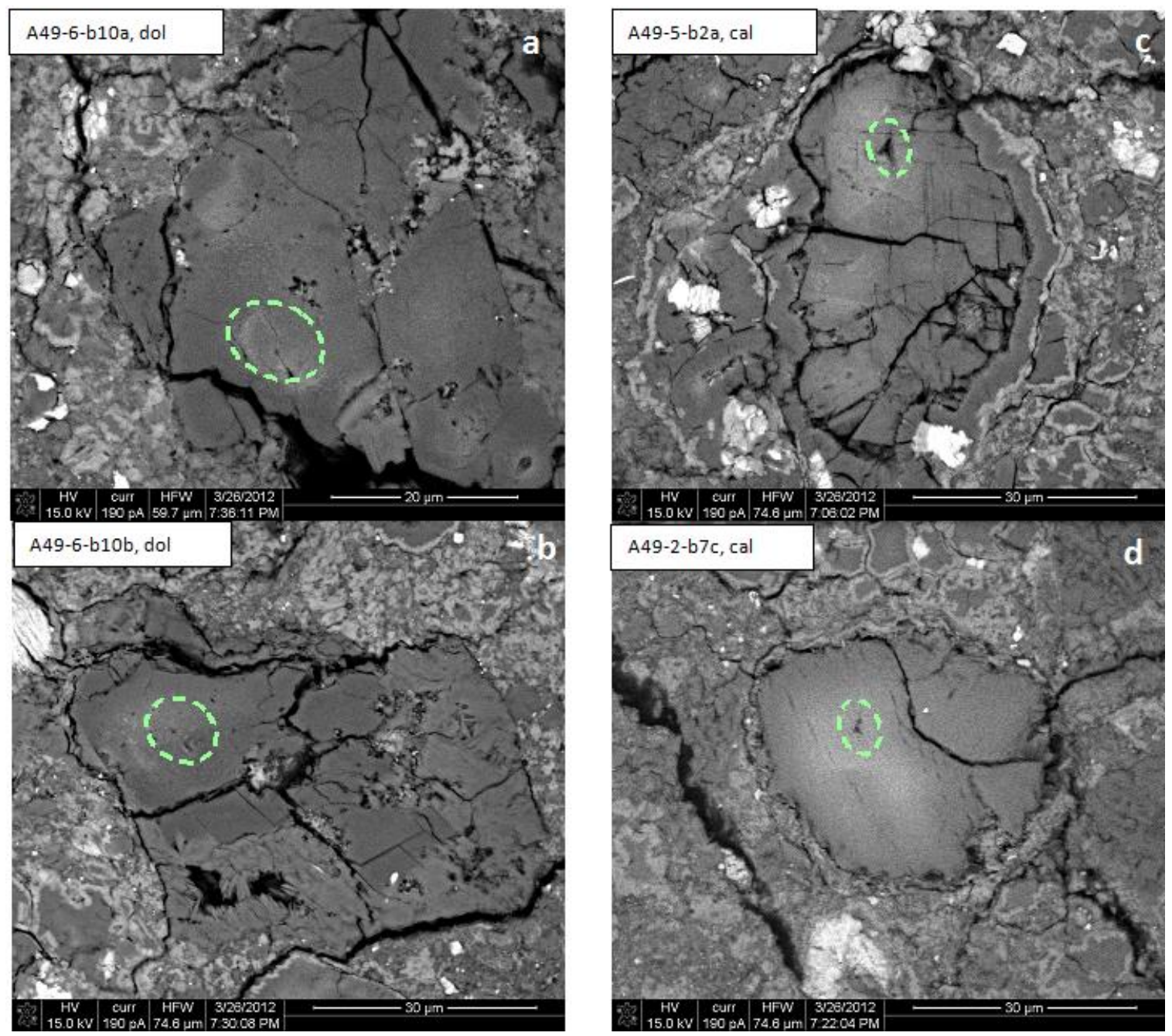
Figure 2. Figures $2 \mathrm{a}$ and $2 \mathrm{c}$ show dolomite $\mathrm{O}$ isotope compositions compared to the chemical composition ( $\mathrm{Ca}, \mathrm{Mg}, \mathrm{Fe}$, and $\mathrm{Mn}$ ) of the area analyzed. Figures $2 \mathrm{~b}$ and $2 \mathrm{~d}$ 795 compare $\mathrm{C}$ isotope composition to the composition of the area analyzed. All four plots show little correlation between isotope composition and chemical composition except in Figure $2 \mathrm{a}$, where there may be a weak relationship between $\mathrm{Ca}$ concentration and $\mathrm{O}$ isotope composition $\left(\mathrm{R}^{2}=0.35\right)$. $\mathrm{O}$ and $\mathrm{C}$ isotope compositions are in permil (\%) vs. VSMOW for $\mathrm{O}$ and PDB for carbon. The cation compositions are reported in mol\%.

800 Isotope errors are $1 \sigma$ and EPMA error is smaller than the symbol sizes. 


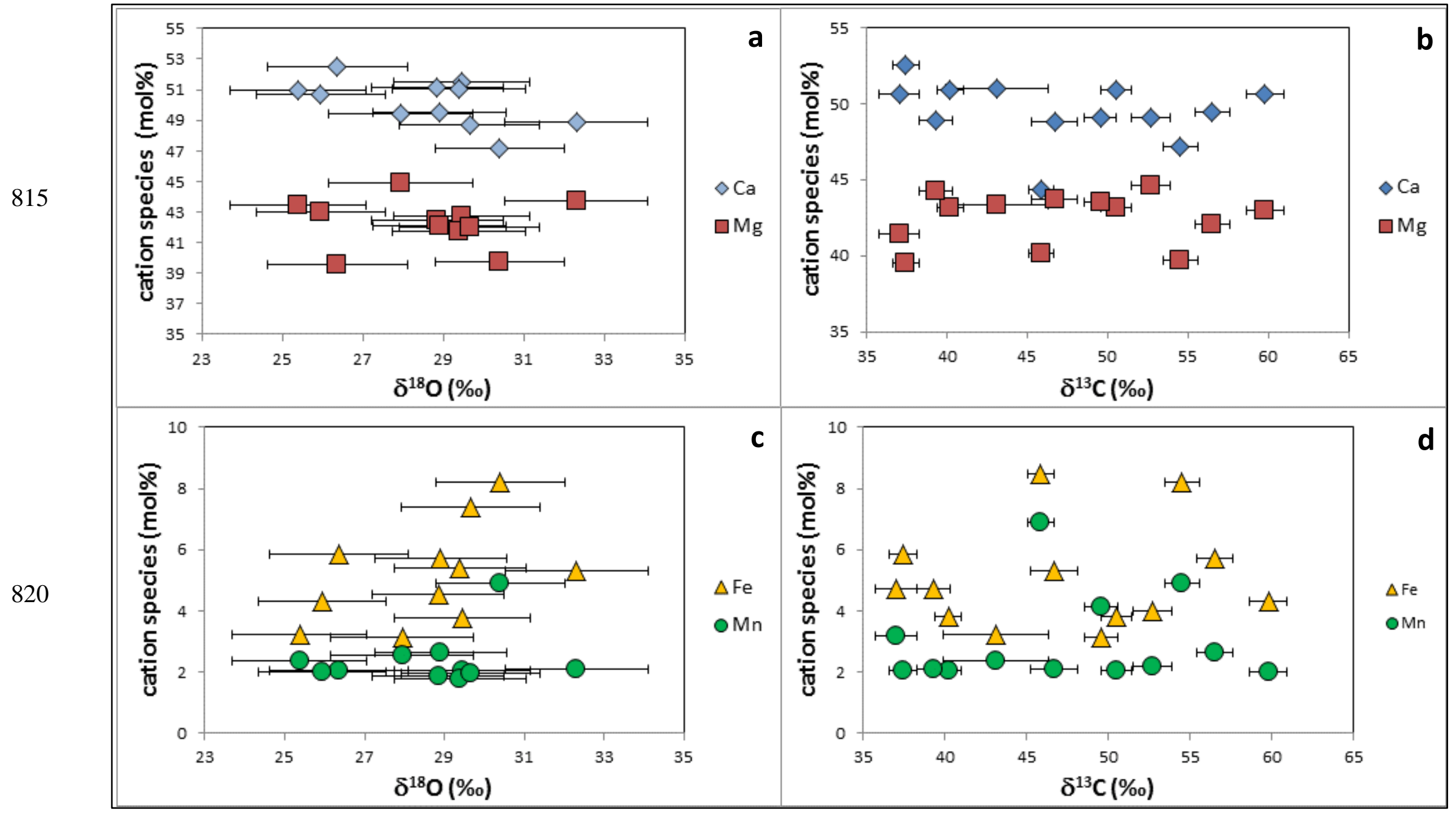


Figure 3. Comparison of the $\mathrm{O}$ isotope composition of analyzed dolomite grains from ALH 84049 with literature data (SIMS analyses) for carbonates from the EET 96006 paired set (Tyra et al., 2007), LON 94101 (Lee et al., 2013), Murchison (Brearley et al., 1999; Bonal et al., 2010), and Sutter's Mill (Jenniskens et al., 2012). Type 1 calcite generally have $\delta^{18} \mathrm{O}$ values $>27 \%$ and type 2 calcite $<25 \%$. Dolomite symbols are larger than calcite and the error bars in calcite have also been suppressed. Dolomite $\delta^{18} \mathrm{O}$ values lie generally in the middle of the range of calcite values. TFL denotes the terrestrial fractionation line, CCAM the carbonaceous chondrite anhydrous mineral line. All analyses are reported with respect to VSMOW.

The inset shows a closed system model where water interacts with anhydrous silicate and evolves, producing progressively lower $\mathrm{O}$ isotope values for both. As the water evolves from point i to $\mathrm{f}$, it becomes lighter in $\delta^{18} \mathrm{O}$ and $\delta^{17} \mathrm{O}$ as denoted by the drawn arrows. The oxygen fractionation factors of water - calcite and water - dolomite are similar at this scale (O'Neil et al., 1969; Kim and O'Neil, 1997; Vasconcelos et al., 2005). The angle between the trajectory of water and that of calcite precipitation from this water has been artificially increased for ease of viewing. Dolomite seems to have precipitated from water midway through its $\mathrm{O}$ isotopic evolution as recorded in calcite.

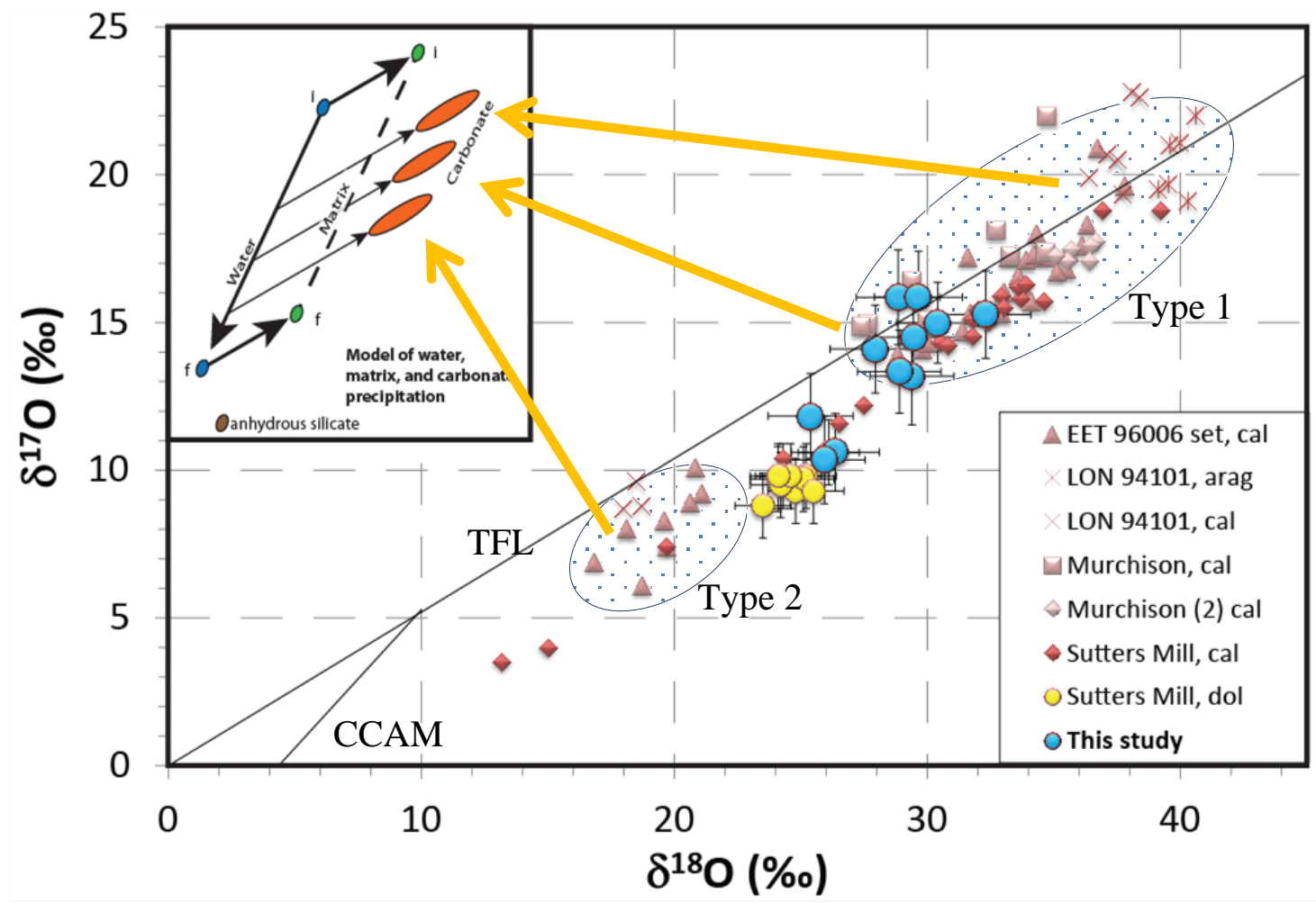


Figure 4. C isotope compositions for dolomite and calcite from this study (orange circles, indicated by letters ' $d$ ' and ' $c$ ', respectively) compared to published bulk carbonate data for different carbonaceous chondrite groups (Grady et al., 1988; Guo and Eiler, 2007; Alexander et al., 2015). Note the distinct separation of $\delta^{13} \mathrm{C}$ values for calcite and dolomite in ALH 84049, and how results from individual carbonate grains in one sample encompass much of the heterogeneity reported from many samples. Uncertainties for the data are smaller than the symbols.

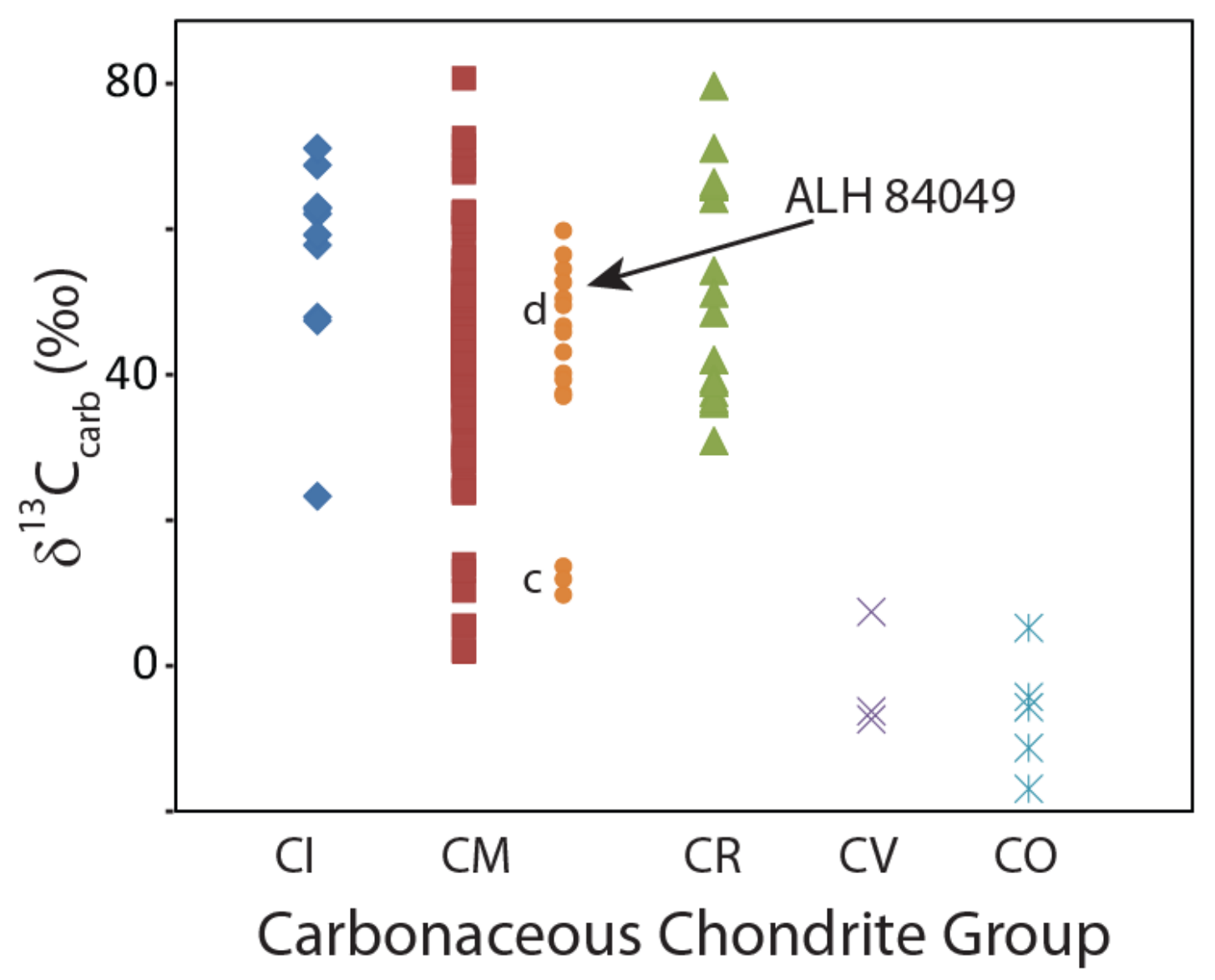


Figure 5. Plot showing the $\delta^{13} \mathrm{C}$ and $\delta^{18} \mathrm{O}$ compositions of single grains of dolomite from ALH 84049 (round, filled orange symbols). There is no apparent relationship between $\mathrm{O}$ and $\mathrm{C}$ isotope compositions in dolomite. Also plotted are bulk CM2 chondrite carbonate data (stars) from Guo and Eiler (2007), which show a similar range to that found in individual dolomite grains. $\mathrm{O}$ isotope compositions are plotted in relation to VSMOW and $\mathrm{C}$ isotopes to PDB.

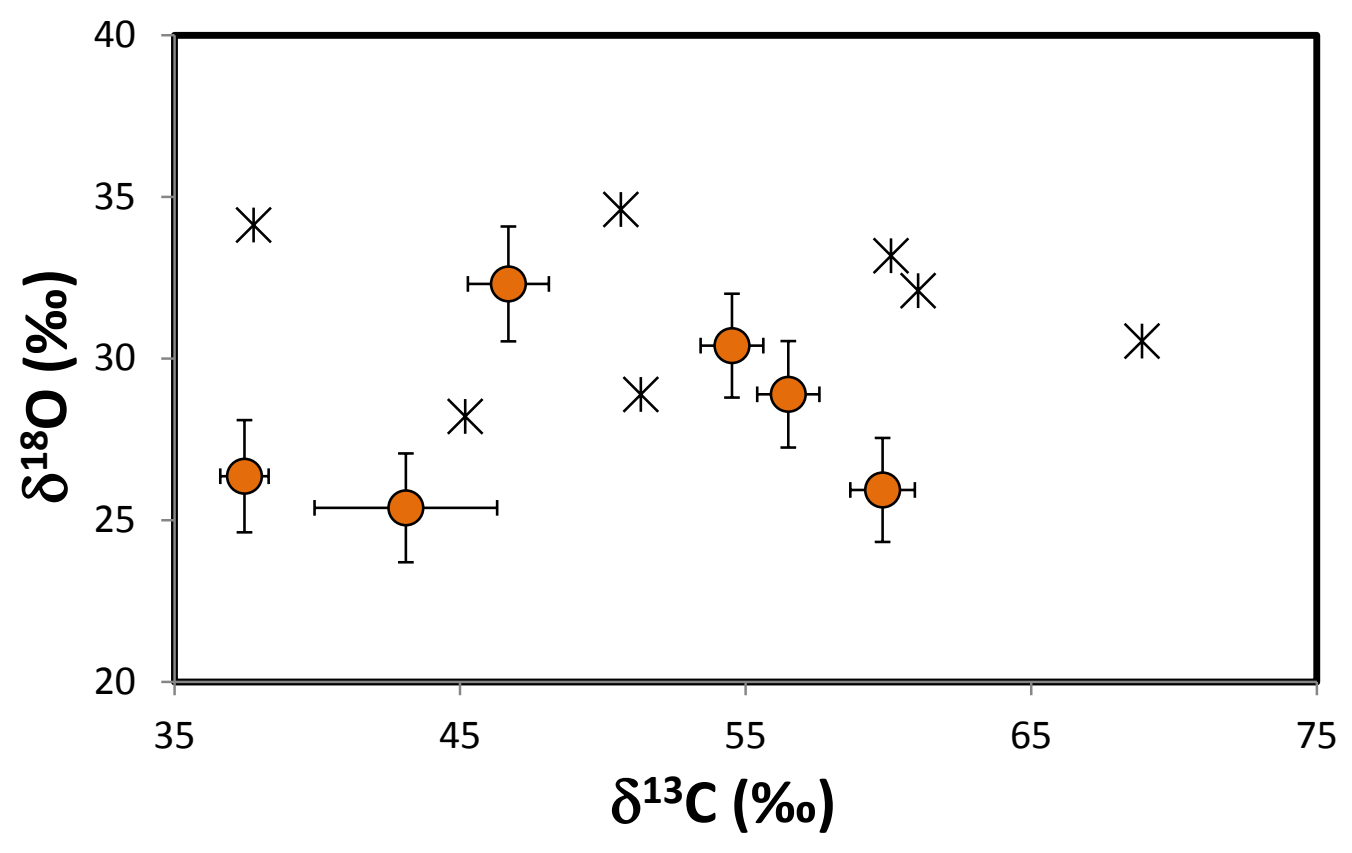

